\title{
Planning and Design Support Tools for Walkability: A Guide for Urban Analysts
}

\author{
Ivan Blečić $^{1}$, Tanja Congiu ${ }^{2, * \mathbb{D}}$, Giovanna Fancello ${ }^{3} \mathbb{D}$ and Giuseppe Andrea Trunfio ${ }^{2}$ \\ 1 Department of Civil \& Environmental Engineering and Architecture (DICAAR), University of Cagliari, \\ 09124 Cagliari, Italy; ivanblecic@unica.it \\ 2 Department of Architecture, Design and Urban Planning (DADU), University of Sassari, \\ 07041 Alghero, Italy; trunfio@uniss.it \\ 3 UMR Géographie-cités (CNRS, Université Paris 1 Panthéon-Sorbonne, Université Paris Diderot, EHESS), \\ 75006 Paris, France; giovanna.fancello@parisgeo.cnrs.fr \\ * Correspondence: tanjacongiu@uniss.it
}

Received: 22 February 2020; Accepted: 20 May 2020; Published: 28 May 2020

check for updates

\begin{abstract}
We present a survey of operational methods for walkability analysis and evaluation, which we hold show promise as decision-support tools for sustainability-oriented planning and urban design. An initial overview of the literature revealed a subdivision of walkability studies into three main lines of research: transport and land use, urban health, and livable cities. A further selection of articles from the Scopus and Web of Science databases focused on scientific papers that deal with walkability evaluation methods and their suitability as planning and decision-support tools. This led to the definition of a taxonomy to systematize and compare the methods with regard to factors of walkability, scale of analysis, attention on profiling, aggregation methods, spatialization and sources of data used for calibration and validation. The proposed systematization aspires to offer to non-specialist but competent urban analysts a guide and an orienteering, to help them integrate walkability analysis and evaluation into their research and practice.
\end{abstract}

Keywords: walkability; planning support tool; review; walkability measurement; walkability evaluation

\section{Introduction}

We present a survey of operational methods for walkability analysis and evaluation, which we hold show promise as decision-support tools for sustainable-oriented planning and urban design. We made an effort to make the survey itself as operational as possible in order to help non-specialist but competent urban analysts to orient themselves and to assist them in meaningfully integrating walkability analysis in their research and practice.

Urban planning and design centered on pedestrians-attentive to their needs, behaviors and perceptions-is receiving a growing attention among scholars, practitioners, and public policy-makers involved in the discussion on sustainability [1-8].

Within that, the concept of walkability has come to occupy a pivotal theoretical and operational role. From being considered a mere question of accessibility analysis applied to pedestrians, the concept of walkability has through debate and practice evolved in a richer, more nuanced, intrinsically multidimensional description of the relationships and interactions among pedestrians, urban space, and its social practices of use.

The concept of accessibility, well established in transportation studies, essentially focuses on the potential of interaction [9] within (urban) space in terms of distances and affordances to reach and partake in urban opportunities (access to goods, services, activities, employment opportunities and 
engagement in public life). But, to assess how "walkable" a place is, it may not be enough to just observe the distribution and the distances of opportunities in space, perhaps in relation to the configuration of the road network and the available transportation options. A growing body of research points at the need to better and more analytically understand other factors that shape the relationships between individuals and urban space: factors related to the quality of the built environment, its conduciveness to be walked and traversed, its capacity to attract and encourage pedestrian mobility in the everyday life, and in general to stimulate people to use and engage with the city [7,10-12]. In many of these studies, besides a question of pedestrian accessibility, walkability is presented as an important factor and catalyst of people's wellbeing and of their overall urban capabilities [13].

Truth be told, many of the essential ideas condensed in the concept of walkability are far from new. Arguments on their bearing on planning and urban design have been around since the mid-twentieth century, championed by scholars like Jane Jacobs, Kevin Lynch, even Camillo Sitte [14-17], and extensively intertwined in the debate on urban quality of life, spatial justice and the right to the city [18-20].

What is new, roughly in the last fifteen to twenty years, is the proliferation of attempts to operationalize the concept of walkability, to develop formal metrics, audit protocols, evaluation methods and tools for design and decision support [2,21-26]. In addition to the growing interest within the theoretical debate, this operational turn was certainly spurred, on one hand, by the increased availability of open geodata, by the development of processing tools and computational techniques, and by the greater capacities of nowadays computer; and, on the other hand, it was motivated by the growing need for effective tools (and models) to support urban planning and decision-making processes concerning alternative spatial development strategies.

The literature on walkability is abundant and includes several survey and review articles [3,23-25,27-29]. With respect to the available survey studies, the specific focus of this work is to provide as much an operational guidance to urban analysts. Therefore, the selection and the systematization of methods and tools for walkability assessment in this study is grounded on a set of criteria (multidimensionality, operationality, transferability and usability, which we describe below), in order to provide orienteering and guidance on those methods and tools we believe may prove to be of the greatest interest and most readily off-the-shelf for use as tools for planning decision and design support.

The paper is structured as follows: in Section 2 we describe different lines of research that characterize the body of literature on walkability and the spatial factors most often employed in walkability assessments. In Section 3 we present the overall design and the procedure we employed to select walkability evaluation methods for our survey, based on the criteria of multidimensionality, operationality, transferability and usability. Section 4 illustrates the taxonomy we developed to categorize and compare the selected methods for walkability analysis and evaluation. The primary output of the survey is the summary table of the selected methods classified according to the proposed taxonomy, which we report at the end of Section 4. A discussion of the results of the classification is proposed in Section 5, before some concluding remarks.

\section{Theoretical Background}

\subsection{Lines of Research on Walkability, A Primer}

Within the growing body of literature on walkability we can distinguish three lines of investigation, although overlapping abounds and thrive.

One first large set of studies focuses on examining the relationships between the walking behaviors and the features of physical environment (e.g., see [2,16,29-37]).

The working hypothesis here is that features of the built environment influence how people choose to travel to work, for leisure, and for active transportation. Positive associations between physical environment and active transportation were found in different geographical contexts, as reported in several reviews articles $[25,28,29,38]$. 
Some studies further investigate the connections between walking behavior, built environment and health [39-42]. For example, Van Dyck et al. [43,44] found that overall walkability and residential density were positively associated with physical activity. Other studies found positive relations between built environment and physical and mental health, as well as life satisfaction [27,45]. Sundquist et al. [46] analyzed moderate to vigorous physical activity and found an association between the frequency of the physical activity and the neighborhood walkability in a Swedish context. Frank et al. [4] assessed how levels of physical activity are related to the measurable aspects of the physical environment near the participant's home, and found that individuals in the highest walkability quartile neighborhoods were 2.4 times more likely to do more than 30 minutes of physical activity per day. The relationship between traffic safety environmental determinants and health was also investigated and gave evidence to various features that influence the risk of pedestrian accidents and hence people's propension to walk $[47,48]$.

A second line of research explores the importance of individual differences, subjective values, and preferences for their behavior and perceptions as pedestrians. It stands as an important body of research since it contributes to the understanding of factors different individuals assign importance to for their walk experience [49-51]. Furthermore, the study of differences in individual characteristics and needs helps to understand how people's abilities influence their use of urban space and their life in cities. In this group, we find many studies focusing on factors of walkability for particular categories of people, for example children $[39,52]$ or the elderly [27,53], or people with disabilities [54] or individuals from different cultural background [55].

Finally, a third line of scholarship aims at framing walkability in more general terms of people's capabilities and quality of life. Walkability is seen as an important factor in human capabilities [10], a determinant of the quality of life in cities, and a contribution to the development of cities' social capital [56-59]. Here, assessing urban walkability is strongly instrumental for the evaluation of people's overall capabilities and their quality of life, by revealing if and how they can reach services, activities, and opportunities by foot and participate in urban life.

\subsection{Spatial Factors of Walkability}

Several attributes related to the physical features of the built environment usually play a prominent role as factors for the evaluation of urban walkability. Among factors most responsible for the conduciveness of urban space to walk-thus supporting or discouraging the act of walking - there are differences in the nature of the attributes measured (measurable environmental features, or self-reported behaviors and perceptions, or evaluative judgements of environmental qualities that affect people's subjective experience of space), in the spatial scale of observation, in the precision of the data collection, and in the method adopted to capture different relevant environmental dimensions [26,27,56,60,61].

While recognizing the multidimensional nature of walkability, Forsyth [3] warns about the diversity of implications the concept can have on urban design and planning policies and thus warns about their incorporation in decision-support systems. Similarly, Krizek [62] stresses how conceptually important and operationally appropriate it is to assign walkability measurement and assessment methods a multidimensional character, that is, "the ability to capture multiple scales and multiple dimensions". The wide range of features included in the assessment models require the organization into dimensional categories.

Since the seminal study of Cervero and Kockelman [63], who proposed the so called "3Ds layout" (Density, Diversity and Design), the list of environmental features has gradually expanded to include many other important factors related to the urban form and functioning, as well as to the behavioral characteristics of pedestrians [28,64]. The research by Gardner et al. [65] for the metropolitan area of London represents a first effort to systematize the desirable attributes of a walking environment into five qualities known as the " $5 \mathrm{Cs}$ " (connected, convenient, comfortable, convivial and conspicuous), which include early stages of individual perception (i.e., disposition of urban environment to promote social interaction and to accommodate people with different abilities). Similarly, the environmental 
audit method and walkability index of Pikora et al. [66,67] includes objective and subjective factors with great detail, with variables divided into four groups: functional, safety, aesthetic and destination. Likewise, Su et al. [68] has proposed an articulation of built environment variables into five groups (connectivity, accessibility, suitability, serviceability, and perceptibility), while the method developed by Ruiz-Padillo et al. [50] combined variables into two main categories: safety and security, and convenience and attractiveness.

Another important contribution to the categorization of the environmental factors of walkability is given by Ewing and Handy [12], who assemble conventional aspects such as activity and transportation factors, urban design attributes and travel behavior, together with some less directly measurable aspects of the cityscape (imageability, enclosure, human scale, transparency, complexity) which affect the experience and the perception of persons during a walk. Consistent with this approach is also the definition for a pedestrian-friendly environment given by Forsyth [3], whose principal environmental requirements consist of traversability, compactness, safety and physical enticement and act as preconditions of perceived outcomes of walking, such as liveliness, sustainable transportation options, or physical activity motivation. Another extensive walkability framework is proposed by Zuniga-Teran et al. [69], who developed a modified version of the more comprehensive LEED-ND neighborhood sustainability assessment method. This framework centered on dividing walkability groups neighborhood design elements into nine categories (connectivity, land use, density, traffic safety, surveillance, parking, experience, greenspace, and community).

In general, in the past two decades, we have seen an important effort to combine spatial and functional attributes of the built environment with pedestrian characteristics and behaviors such as individual perceptions, preferences, attitudes, and conduct in urban space according to one's abilities. Many studies resorts to both data collected on the field (by mean of audit and GIS supported data mining) and data derived from respondents (mainly collected through surveys, questionnaires, or interviews).

One relevant difference among the methods resides in how the factors of walkability have been operationalized in the measurements $[24,26,34,60]$. Since qualitative data are often more appropriate to capture the effective behavioral aspects, they are commonly used to supplement, validate, and explain quantitative data gathered in a given environment; therefore, qualitative data are often employed for calibrating and validating analytical and assessment models. Quantitative analysis, on the other hand, are more suitable to objectively identify and quantify the descriptive aspects of the built environment (distinguishing characteristics, features, and elemental properties) and to yield statistical evidence of the relationships among observed features and the strength of such relationships.

Undoubtedly, the possibility of combining objective with subjective data, as well as quantitative and qualitative analytical techniques, permits a more complete and specific description and understanding of the processes (elements, their interactions, and relative weights) which influence walking in urban areas [70]. Therefore, the combination of methodologies, namely triangulation in the operational research theory, turns out to be a powerful way to gain insights and to assist scholars and practitioners in making inferences and in drawing conclusions [71,72]. This approach is particularly effective and useful in addressing planning and decision-making processes sensitive to the behavioral concerns of urban space, as it allows us to recognize and explore the relationships between the physical environment and the human responses to that environment.

\section{Survey Design}

\subsection{Search Strategy}

For the preliminary selection of the walkability assessment methods, we carried out an extensive search on Google Scholar, Elsevier's Scopus and Clarivate Analytics' Web of Science for papers on the measurement and evaluation of walkability for planning and design support. We searched for scientific literature using keywords "walkability", "measur", and "planning support", and similar or 
related terms like "pedestrian access", "evaluation", "assessment", and "decision making". The search results were rather numerous and have increased substantially since 2011 (Table 1), thus confirming the growing interest in the topic. The academic areas mostly represented (with more than ten papers) were: medicine, social sciences, environmental science, nursing, engineering, health professions, arts and humanities.

Table 1. Number of papers for keywords and year range.

\begin{tabular}{ccccc}
\hline & Walkability & $\begin{array}{c}\text { “Walkability" + } \\
\text { "Measure" }\end{array}$ & $\begin{array}{c}\text { “Walkability" + } \\
\text { "Planning Support" }\end{array}$ & $\begin{array}{c}\text { “Walkability" + } \\
\text { "Evaluation" }\end{array}$ \\
\hline Scopus & & & & 4 \\
$(2000-2005)$ & 26 & 9 & - & 19 \\
$(2006-2010)$ & 193 & 92 & - & 54 \\
$(2011-2016)$ & 739 & 347 & 5 & 36 \\
$(2017-2019)$ & 555 & 247 & 4 & 3 \\
Web of Science & & & & 11 \\
$(2000-2005)$ & 20 & 8 & 2 & 37 \\
$(2006-2010)$ & 182 & 93 & 7 & 36 \\
$(2011-2016)$ & 810 & 274 & 43 & 540 \\
$(2017-2019)$ & 561 & & & 2410 \\
Google Scholar & & 746 & 9 & 8340 \\
$(2000-2005)$ & 1070 & 2750 & 46 & 4790 \\
$(2006-2010)$ & 4570 & 11,700 & 254 & \\
$(2011-2016)$ & 14,700 & 5210 & 141 & \\
$(2017-2019)$ & 9500 & & &
\end{tabular}

All the employed sources (we considered thematic articles published in recent years in peer reviewed journals, together with review papers and book chapters) have been useful for identifying the most widely used walkability measurement and evaluation methods and obtaining a preliminary overview of the operational advancements accomplished in the last two decades.

\subsection{Study Selection}

Titles and abstract were screened for the eligibility of papers. All the articles with irrelevant titles and abstracts were excluded. Then, we selected only those papers which presented a method that offered an actual contribution to operationalizing the concept of walkability and those with the aim to support urban planning and design and decision-making processes.

In line with the aim of this paper, a second round examination considered the adherence of each study to a list of requirements distinctive of decision-support systems defined on the base of the literature about decision-support systems and on the academic and professional experience of the authors. The structural characteristics of the methods used as criteria of inclusion are described in Section 3.3. This analysis led to 47 methods and tools (see Table S1 in the online supplemental materials).

Finally, we develop a taxonomy for an in-depth examination of the selected walkability measurement and evaluation methods.

Since some studies adopted the same walkability measurement method, a final subset of 30 methods was selected to be analyzed according to our taxonomy. The list cannot be considered exhaustive, but it provides a reasonable overview of the current main trends in the literature on the methods for walkability evaluation and decision and design support.

\subsection{Criteria of Inclusion}

For the selection, we considered methods which meet the requirements of multidimensionality, operationality, transferability, and immediate usability. Scholars and practitioners in the field of decision support acknowledge these qualities as critical for the effectiveness of the operational tools [73-76].

More precisely, the selected studies:

- Develop an operational method for the evaluation of walkability, offering an explicit measurement procedure and/or algorithm for the analysis and assessment of urban walkability; 
- Adopt a multidimensional approach to the walkability measurement that considers the main factors of walkability usually mentioned in literature (tools for partial evaluation of just a few factors of walkability were excluded);

- Are reasonably user-friendly, usable, and transferable to different urban contexts; we considered the type and availability of data used, their ease and quickness to collection and clarity of implementation with the greatest importance given to the possibility of automation;

- Observe accuracy and details in the analysis and outcomes; the scale of data used for measurement, the precision of data gathering, and the characteristics and quality of results are indicators of this requirement;

- Pay attention to the quality of presentation, readability, and meaningful interpretation of the outputs and results of evaluations (methods and tools producing detailed spatialized outputs were privileged);

- Take into account human diversity: values, preferences, characteristics are important to consider not only for the legitimization of a policy, but also for a participative and active definition of the knowhow of policy-makers and citizens; these data are predominately subjective, so we selected methods which use or envisage their use for the calibration and validation of the model;

- Give the possibility not only to analyze but also to evaluate and consciously choose between alternatives; the possibility to spatialize results and the detail of outcomes are useful support for decision making.

\section{A Taxonomy for Walkability Evaluation Models for Planning and Decision Support}

We propose a taxonomy to analyze the selected methods with respect to their potential applicability and usefulness as tools for decision and design support.

With this taxonomy, we strive to guide the urban analyst in the examination and selection of a decision-support tool for the analysis of walkability-oriented policies.

In the following subsections, we define the terms of the taxonomy we have developed in order to present, compare, and classify the selected methods. Besides its expediency for comparing methods, we have devised this taxonomy also as the set of requirements we suggest that a planning support system should possess in order to be an effective guide for a comprehensive and integrated improvement of urban walkability, and hence of the urban quality of life.

The main elements of the taxonomy, described in following subsections, are:

- The (spatial) "factors of walkability" indicative of the multidimensional approach and the analytical precision observed (family, type, method, and scale of data processed) (Table 2 in Section 4.1);

- The possibility of "profiling" among different categories of people, which reveals an attention to human diversity ( Section 4.2);

- The "aggregation model" used, which is useful to implement the method but also to increase awareness about its methodological values and limitations ( Section 4.3);

- The "spatial" scale of results, giving information about the accuracy of the evaluation and its relating significance and value (Section 4.4);

- The data used for the "calibration and validation" of the model, indicative of the reliability of the walkability model (Section 4.5).

Table 3, at the end of this section, is the compendium of the taxonomy we propose. It sums up all the reviewed studies that met the methodological and operational requirements mentioned above -multidimensionality, operationality, transferability, and immediate usability — and summarizes the main concerning information we took into consideration to categorize and compare methods. Therefore, Table 3 should be seen both as the primary output of this work and a guide to help readers follow our line of argumentations throughout the text. 


\subsection{Factors of Walkability}

Taking into consideration the conceptual categorizations proposed in the literature, we grouped features of urban environment into four families of indicators: (1) efficiency and comfort; (2) safety security and certainty; (3) pleasantness; and (4) attractiveness. These we believe summarized the environmental aspects at different scales that most influence the susceptibility of urban space to be walked, and, what is more important, to enhance the potential of the built environment to enable the majority of people to effectively "use" the city and its opportunities starting from the (differential) individual abilities of people $[77,78]$. The defined families of factors are not mutually exclusive as they gather together distinct but complementary attributes that contribute to the assessment of pedestrian accessibility.

Table 2. Factors of walkability.

\begin{tabular}{|c|c|c|c|}
\hline Family & Description & Examples of Factors/Indicators & References \\
\hline $\begin{array}{l}\text { Efficiency \& } \\
\text { Comfort }\end{array}$ & $\begin{array}{l}\text { Convenience and ease of walking } \\
\text { and freedom from hardship and } \\
\text { constraints. Includes physical } \\
\text { features that influence practically } \\
\text { the use of urban space by foot, } \\
\text { both as supporters and } \\
\text { detractors. }\end{array}$ & $\begin{array}{l}\text { Cost expressed in distance, time, directness } \\
\text { and continuity of route, path slope, } \\
\text { sidewalk width, presence of shelters and } \\
\text { shade, sedibility, street lighting, pavement } \\
\text { maintenance, signalization and information, } \\
\text { accessibility by different transport modes, } \\
\text { number and time frequency of transit } \\
\text { service, availability of parking facilities }\end{array}$ & {$[2,7,60,66,69,79-83]$} \\
\hline $\begin{array}{c}\text { Safety, Security, } \\
\text { Certainty }\end{array}$ & $\begin{array}{l}\text { Exposure of pedestrians to traffic } \\
\text { risk (including factors of conflicts } \\
\text { and interference or protection) } \\
\text { and the personal sense of security } \\
\text { and certainty transmitted by } \\
\text { urban environment. }\end{array}$ & $\begin{array}{l}\text { Car traffic volume, design speed of the } \\
\text { route, on-street parking, geometry of } \\
\text { crossings and facilities for pedestrians at } \\
\text { crossings, coexistence or conflicts with other } \\
\text { modes (separation features, traffic calming } \\
\text { measures, surface texture, signalization), } \\
\text { transparency and permeability of built } \\
\text { environment, presence and type of } \\
\text { activities, hours of operation, street lighting, } \\
\text { landmarks, crime/police presence, urban } \\
\text { space maintenance, cleanliness, pedestrian } \\
\text { activity and natural surveillance. }\end{array}$ & {$[2,24,48,60,66,69,80-84]$} \\
\hline Pleasantness & $\begin{array}{l}\text { Sense of place and "vibrant } \\
\text { atmosphere" infused by urban } \\
\text { space which encourage } \\
\text { pedestrian to spend time in. }\end{array}$ & $\begin{array}{l}\text { Site atmosphere, aesthetic of places, } \\
\text { architectural and landscape design, scenery, } \\
\text { cleanliness, pedestrian activity, noise level, } \\
\text { transparency and permeability of built } \\
\text { environment, urban texture. }\end{array}$ & {$[2,7,12,60,66,69,80,82,83]$} \\
\hline Attractiveness & $\begin{array}{l}\text { Presence, type and level of urban } \\
\text { opportunities and services } \\
\text { achievable and reachable by foot. }\end{array}$ & $\begin{array}{l}\text { Number, density, size, diversity (land use } \\
\text { mix, entropy index), hours of operation, } \\
\text { frequency service of human activities. }\end{array}$ & {$[1,2,12,33,34,62-64,69,80,83]$} \\
\hline
\end{tabular}

The taxonomy of four families we propose is based on the nature of the variables commonly used in assessment. So, "efficiency and comfort" encompass topological characteristics of the road network and spatial qualities that contribute to physical ease; "safety, security and certainty" refers to perceptible and physically measurable attributes of the walked environment that affect people's perception of being protected from traffic and crime and of being walking in the right direction; "pleasantness" relates to the sense of enjoyment and satisfaction transmitted by the urban-design qualities people experience while walking; and, finally, "attractiveness" refers to the land use patterns and to the number, class, and location of urban attractors and opportunities.

In Table 2 we offer a description of the main factors considered for each family and provide some examples of the most widely used indicators found in the literature with their respective references.

We classified each family of features with respect to (see Table 3):

- The level of exhaustiveness $\left({ }^{*}\right.$ basic, ${ }^{* *}$ medium, or ${ }^{* * *}$ high, depending on the number and variety of attributes considered);

- The type of data (objective measures $(\mathrm{M})$, evaluative judgment $(\mathrm{J})$ or hedonic state $(\mathrm{H})$ ); 
- The method of data collection (direct survey (D) or provided by external sources (E) such as census database, open data, user generated contents apps); scale of observation (street level, block, census tract, catchment area, neighborhood, city-level). These qualities were used respectively as indicators of multidimensionality, accuracy and precision of the measurement method and its suitability.

According to the basic subdivision into four families of factors, the selected walkability evaluation methods revealed that even though, overall, many studies of walkability transversally touch all the families, thus proving to adopt a multidimensional approach, single methods differ in the emphasis given to certain families and in the way of operationalizing the measurement. Some studies focus mainly on the safety and efficiency of space [81,85], others look at the attractiveness of the city $[1,28]$ and still others are more sensitive to pleasantness [7,10,86,87].

Moreover, depending on the study the same variable can support different interpretation. For example, street lighting contributes to enhance the sense of security of walking along the street $[2,32,63,66,69,82]$ and makes the same street more comfortable as well [60]. Road trees offer comfort from the sun $[30,60]$, make the roadscape more pleasant $[66,68]$, and enhance the imageability of the road.

Operational and methodological choices are influenced by the double nature of the variables interested in the walkability measurement. Many of the selected studies resort to objective variables $(\mathrm{M})$, that is observable data (characteristics, phenomena, resources, individual status) that can be measured objectively by anybody with standard and replicable protocols (for example geometry and design of streets, volume of cars and users). This methodological preference responds to the requirements of transparency and reproducibility of the methods in different urban contexts. The use of subjective variables which encompass evaluative judgments (J) (personal opinion about a phenomena, resource, service, .... .) and hedonic states $(\mathrm{H})$ (personal state of pleasure or satisfaction of individuals), are most often restricted to the phase of model validation, being such type of information more appropriate to explain the meaning of the collected quantitative data. Emery, Crump and Bors [84], for example, tested the reliability and validity of their assessment instrument of the suitability of sidewalks for walking by comparing the final score resulting by an on field audit method applied to a sample of 31 road segments with the evaluation of the conditions of the same roads expressed by a panel of experts based on a seven-point Likert response system. Likewise, in order to reduce arbitrariness in the determination of the weights of built environment variables included in composite measures of walkability, Ruiz-Padillo et al. [50] proposed a method based on the comparison of three different type of decision analysis techniques (fuzzy Analytic Hierarchy Process, Kendall rank correlation method, and six different Social Choice Functions). Nonetheless, a number of studies, especially in the field of active living, resort to subjective interpretations of quantitative physical features usually obtained through survey questionnaires $[42,45,88,89]$. However, the elaboration of subjective indexes can be difficult to understand for non-expert analysts and may be costly and time consuming. To overcome these problems, Boulange et al. [22], adapted the CommunityViz 5.1 system to develop a multipurpose and versatile GIS-based planning support system to be used for walkability assessment of an area and for the estimation of how the area will change under various urban development scenarios

With regard to the scale of observation, the inclusion in walkability measures of many of the mentioned environmental factors requires a micro-level analysis, a deep and detailed observation of the physical space, and a particular attention in the aggregation and transformation of data [2,79]. However, fine-grain observation is resource- and time-consuming. In this sense, the possibility for analytical and measurement methods to be automatized by use of ICT and GIS applications represents an important advancement for a systematic implementation of such instruments in planning and design decision making. Giles-Corti et al. [90], designed an open-source user-friendly tool to assess urban walkability with the aim to assist policy-makers to evaluate and monitor planning and policy decisions and to support practitioners in advanced measurement of neighborhood attributes using data sourced from official portals. 


\subsection{Profiling}

Model profiling, intended as the inclusion of information about categories of users in diverse stages of the evaluation process, represents another important requirement for the effectiveness of walkability assessment methods. This is an especially relevant feature for capability-centered planning support tools meant to assist planners, architects, and decision-makers to define and discuss design interventions and measures for a more accessible and inclusive urban environment. The understanding of the needs, attitudes, and preference of different categories of people becomes fundamental for the design of walkable urban settings (endowed) with physical and functional attributes that enable persons with different characteristics and abilities to freely choose and exercise their functionings [13]. Improving pedestrian accessibility level and quality represents one step towards this goal $[77,78]$.

For this reason, the consideration for user profiling (the column "Profiling" in Table 3) was included in our examination of the walkability evaluation methods.

Most of the studies on urban walkability elaborate methods aiming to analyze accessibility with respect to a specific goal (category of people, type of activity). A number of studies refer to specific segments of the population, with the predominance of children and the elderly [27,39], while variables concerning socio-economic status (e.g. car ownership, income), gender, age, or personal abilities and disabilities, when included, are used as covariates. For example, once they had defined the relative importance of walkability variables, Ruiz-Padillo et al. [50] resorted to stratifications of values for gender, age, number of walking trips per week, and number of cars owned. In this way certain similarities or differences among groups of people become visible and could be addressed to planning interventions. A profiling procedure was adopted by Moura et al. [81], who developed a walkability measure for distinct pedestrian groups (adults, children, seniors, and impaired mobility pedestrians) with the aim to evaluate the ease or difficulty of walking and to support policies and actions towards more inclusive pedestrian environment.

\subsection{Aggregation Model}

The aggregation model (the column "Aggregation" in Table 3) describes how the factors of walkability are combined in the evaluation model to yield aggregate indices and assessments. We distinguish aggregation models into compensatory and non-compensatory. The former allows for the performances over attributes to be compensated among each other. Compensatory models include linear (L, i.e., weighted sum) and nonlinear (NL) combinations of attributes. Many studies construct the final indexes based on additive models. They consist of composite measures of walkability obtained by summing and standardizing objective and subjective attributes of the built environment, with the "3Ds" of Cervero and Kockelman [63] used as the basis, enriched from case to case with further factors $[4,32,44,53,69]$.

Some, but not many, methods do try to avoid (complete) compensation among criteria by adopting some non-compensatory (NC) aggregation models. An example is given by the authors of [91], who used a "nested" ELECTRE TRI model to assess the walkability from a microanalysis of the available opportunities in space and of the features of the street network, its environmental and design aspects.

\subsection{Spatial Scale of Results}

The spatial scale of the evaluation results (the column "Spatialization" in Table 3) is another criterion we considered relevant. It influences the detail of the visualization and the readability of the outputs, especially by non-experts. We distinguish between different spatial scales, considering the detail of the outputs: neighborhood level, block/census tract level, street level, and sub-street level (e.g., nodes, segments, pixels in a rasterization). The visualization of data and results encourages a more extensive adoption of walkability assessment methods so that they can be handled not exclusively by researchers and highly skilled urban and transport planners, but also by users with basic spatial awareness skills such as politicians and decision-makers. 
Many of the analyzed methods offered a spatialization of results which differ for the scale of representation. The Neighborhood Environment Walkability Survey (NEWS) index [4,35,42,44,56,87] and the walkability planning support system of Boulange et al. [22] offered a final measure of walkability at the neighborhood level, while the outputs of Glazier et al. [31] and Giles-Corti et al. [90] are referred to census tracts. A deeper level of detail is observed by other studies whose final measures concern road $[7,68,81]$ and sub-street levels (e.g., nodes, segments of roads, pixels in a rasterization) $[10,62,92,93]$.

Examples are given by Walkscore (http://www.walkscore.com/) and Walkshed (http://www. walkshed.org/), two tools notable for their user-friendly interface and for easy and dynamic representation of the spatial data. Walkscore produces heat maps that may be used by the analysts of the real-estate market, public health, and urban planners. Walkshed not only generates heat maps, but also calculates one's own walkability score, by allowing the user to define priorities (weights) of different types of destinations distributed in space.

The spatialization of results and the possibility to handle spatial scales facilitates the recognition of differences among places, parts of the city, and single roads segments. These qualities turn out to be particularly useful to detect spatial and social inequalities and pinpoint the consequent improvement actions.

Su et al. [68] developed an auditing street walkability method whose results helped planners to identify social inequalities in the accessibility to urban opportunities and to inform integrated land use and transport planning options to overcome disparities.

\subsection{Calibration and Validation}

Another criterion of our taxonomy is whether the method has been calibrated and validated, or if it is at least suggested how that can or should be done. This aspect is indicative of the validity and reliability of models and hence of their transferability. Calibration and validation are two different steps. Calibration allows us to estimate parameters (criteria, scales, weights, etc.) of the evaluation model, while validation is the comparison of results of a calibrated model against observed data. Both stages imply the comparison between the model and the real system observed. For this purpose, the availability and the quality of data used to describe the real functionality of the studied context becomes crucial.

We examined walkability studies and made a distinction based on the kind of data the authors use (or recommend using) for the calibration and validation: revealed behaviors (RB), stated preferences (SP), or a panel of experts (EX).

Revealed behaviors are usually used to validate the results of the model ("where do people walk?") and to derive the preferences ("which areas are the most walkable?"). They can be collected with different methods, like GPS tracking, accelerometers, surveys, and so on [12,31,56,80,93-95]. Stated preferences can be used and collected with audits, questionnaires, and interviews, and are useful to reveal (the stated) motives behind people's choices. 
Table 3. Summary of reviewed studies




Several researches organize panels of experts (EX) in order to calibrate and validate the evaluation method. Among these, Ewing and Handy [12] involved specialists to define the set of variables as well as the possible methods of analysis of the urban walkability. Hajna et al. [32] found high correlation (Spearman coefficient) between on-site audit (made by trained research assistants) and GIS measures and concluded that the measures obtained with GIS can be used in place of labor intensive neighborhood auditing methods. Oswald Beiler and Philips [82] used the Analytic Hierarchy Process multicriteria decision-making method to rank pathways metrics based on their relevance and importance toward pedestrian improvement projects. A pairwise comparison survey was distributed to experts in order to determine the relative weights of factors that influence walkability.

\section{Discussion}

As previously stated, the recourse to our taxonomy is strictly functional to our primary intent to offer a methodological guidance to the operational use of walkability evaluation as decision and design support tool for urban planning practice. Indeed, the usability and suitability of the measurement methods are profoundly influenced by the availability and the quality of data (source, type, level of detail, method of collection), as well as by the capacity of analysis and interpretation of the metrics (aggregation model, spatialization, profiling, calibration and validation).

The examination of methods and tools revealed a distinction between those directed to the academics and those more directed to the practitioners, with the former group prevailing. This goes hand-in-hand with the propensity of scholars for innovating, advancing and refining models, with the aim of enhancing their precision and reliability, which comes sometimes to the detriment of simplicity of use and interpretation of results. However, the complexity sometimes undermines the direct practical applicability of methods. At the same, time methods which are more suitable for non-experts tend to simplify to the detriment of precision and specificity. The attempts of some researchers to compensate this unbalance should guide further work in this field.

With regard to the attributes of methods considered in our taxonomy, the completeness of the walkability factors included in the evaluation method is fundamental to ensure multidimensionality, but constitutes a challenge for two main reasons: (1) the set of factors adopted differs from method to method, making comparison difficult; (2) data collection is a time- and resource-consuming activity.

Despite the extensive and creative development of walkability analytical models, there is no universal consensus about an exhaustive set of criteria to consider. The four families of environmental factors considered in our taxonomy encompass the most occurring and objectively measurable aspects included in walkability evaluation. They have to be intended as indicative qualities to regard, then, the specific variables used can differ, depending on the perspective and the targets of each study, program duration, available funding, etc. For example, health-oriented studies focus most on environmental determinants of walking and prefer objective measures while the models developed by transport and land use researchers consider spatial features that affect the safety and convenience of paths and give emphasis to the experience of walking as well by combining quantitative and qualitative variables.

A second challenge is related to the large effort that direct data collection requires. The examined methods presented a prevalent tendency to collect data in the field, although a number combine external sources data gathering (mainly from open source datasets) with direct collection. Many recent tools resort to some form of automated data collection and big data analytics. We believe automation represents one of the new frontiers of the research on walkability models [21].

The increasing use of open geodata contributes to broadening the availability and accessibility of basic information, making data collection and analysis procedures simpler and replicable. Spatial web services and social network platforms for example enable the collection of both objective and subjective data more quickly and easily. New and growingly ubiquitous technologies (e.g., GPS tracking, sensors, social networks data, open data) are useful tools for conferring smartness to decision-support tools and urban policy making. Such technologies can support the collection of information on the micro-level 
that cannot be gathered without expensive efforts by simple audit tools or existing administrative datasets. In sum, open source geodata and software increase both the operationality and usability of walkability assessment methods. The ability to encompass and integrate both objective and subjective information is another important requirement of walkability-oriented planning support systems. Our investigation has shown that subjective data are usually used for model calibration and validation, while the attempt to customize the analytical and assessment functions as well as the results according to the intrinsic characteristics of the users (profile of individuals or social groups) and places (catchment areas, neighborhoods, city, regions) is limited only to a few tools analyzed. The analyzed tools were lacking in this aspect. Future work should give more emphasis to the attributes of target populations (habits, sociocultural peculiarities, attitudes, preferences) and to the geographical context (information on geographical setting and its characteristics) in order to better identify singularities and differences to take into account in the evaluation and to make the models more reliable and complete.

The ability to spatialize and visualize data and results, as well as the possibility to dynamically interact with the analytical and evaluation model by increasing precision or introducing new functionalities, make some instruments more suitable to support effectively planning and design processes and give a real contribution to the improvement of spatial behaviors and quality of life. In this regard, the most promising fields of research are about the above-mentioned technological advancements in data capturing and processing and in the representation and communication of outcomes [22]. For example, the availability of visual support by mean of maps and diagrams, interactive interfaces, visual scenario representation, makes it easier to pinpoint spatial and social inequalities in the distribution of pedestrian accessibility, or give immediate evidence of the impact of specific choices. It can support actors in prioritizing decisions on pedestrian accessibility and assist in the allocation of funding. In such ways, decision-support methods enhance their communicative value by becoming easier to understand and interpret by non-experts.

Finally, the scale of aggregation of data, results, and outcomes is also important, as it allows planners and researchers to manage different levels of detail and different views of the study context, thus revealing relationships, correspondences, or mismatches among factors of walkability and the dimensions of the city.

\section{Conclusions and Recommendation for Future Work}

In this paper we have presented a survey of operational approaches for measuring urban walkability, which are potentially useful as tools for urban decision and design support. We have developed a taxonomy for the comparison of different evaluation methods. The taxonomy, besides proposing a way to systematize the state-of-the-art research on walkability, also offers a set of requirements that we suggest a decision and design support tool should have in order to effectively incorporate the paradigm of urban walkability into urban planning and design strategies, whilst being sensitive to sustainable concerns and attentive to the interaction inhabitant-city.

The study presents limitations. First, the reviewed models apply a wide variety of approaches of conceptualizing and operationalizing urban walkability. This inevitably led to a lack of uniformity among methods, which makes comparison difficult. For this reason, the discussion on selected methods was not based on the specific outcomes and on their reliability, but instead on how the model is structured according to its adherence to the requirements we adopted for decision-support purposes (multidimensionality, operationality, transferability, and immediate usability).

Second, but strictly connected to the first point, for several selected methods, the data used are not easily available and accessible. This may sometimes cloud the full understanding of how the tool works, and how its methodology and outputs may be validated. For this reason, a broader willingness of researchers to make the data and the data processing code and routines available needs to be encouraged in the future.

One last observation goes to the future challenges in urban accessibility analysis and evaluation. The methods analyzed in this paper can be conceived as planning-support tools, as they assist 
policy-makers in facing long-range problems and developing strategies for the territory. However, we believe that such decision-support methods should go beyond the analysis and assessment of space (either objectively measured and evaluated subjectively), making the analytic process more flexible and inventive, for example by revealing unprecedented sets of alternatives to the decision problem unexpected at the beginning of the policy-making cycle. This creative effort is one of the new challenges not only for urban planning but for the whole public policy field. In conclusion, we hope that the proposed taxonomy of walkability assessment methods can represent a methodological and operational aid for planning researchers, urban analysts, and decision-makers involved in the formulation of policy strategies aimed at enhancing the walkability and the quality of urban space.

Supplementary Materials: The following are available online at http://www.mdpi.com/2071-1050/12/11/4405/s1. The following are available online at Table S1: Reviewed studies.

Author Contributions: Conceptualization, I.B., T.C., G.F. and G.A.T.; Formal analysis, T.C. and G.F.; Methodology, I.B., T.C., G.F. and G.A.T.; Supervision, I.B. and G.A.T.; Writing - original draft, T.C. and G.F.; Writing - review \& editing, I.B., T.C. and G.F. All authors have read and agreed to the published version of the manuscript.

Funding: This research received no external funding

Conflicts of Interest: The authors declare no conflict of interest.

\section{References}

1. Cervero, R.; Duncan, M. Walking, bicycling, and urban landscapes: Evidence from the San Francisco Bay area. Am. J. Public Health 2003, 93, 1478-1483. [CrossRef] [PubMed]

2. Clifton, K.J.; Livi Smith, A.D.; Rodriguez, D. The development and testing of an audit for the pedestrian environment. Landsc. Urban Plan. 2007, 80, 95-110. [CrossRef]

3. Forsyth, A. What is a walkable place? The walkability debate in urban design. Urban. Des. Int. 2015, 20, 274-292. [CrossRef]

4. $\quad$ Frank, L.D.; Sallis, J.F.; Conway, T.L.; Chapman, J.E.; Saelens, B.E.; Bachman, W. Many pathways from land use to health. J. Am. Plan. Assoc. 2006, 72, 75-87. [CrossRef]

5. Livi, A.D.; Clifton, K.J. Issues and methods in capturing pedestrian behaviors, attitudes and perceptions: Experiences with a community-based walkability survey. Transp. Res. Board Annu. Meet. 2004, 1-17.

6. Páez, A. Mapping travelers' attitudes: Does space matter? J. Transp. Geogr. 2013, 26, 117-125. [CrossRef]

7. Porta, S.; Renne, J.L. Linking urban design to sustainability: Formal indicators of social urban sustainability field research in Perth, Western Australia. URBAN Des. Int. 2005, 10, 51-64. [CrossRef]

8. Speck, J. Walkable City: How Downtown Can Save America, One Step At a Time; North Point Press: New York, NY, USA, 2012; ISBN 978-0-374-28581-4.

9. Hansen, W.G. How accessibility shapes land use. J. Am. Inst. Plann. 1959, 25, 73-76. [CrossRef]

10. Blečić, I.; Cecchini, A.; Congiu, T.; Fancello, G.; Trunfio, G.A. Evaluating walkability: A capability-wise planning and design support system. Int. J. Geogr. Inf. Sci. 2015, 29, 1350-1374. [CrossRef]

11. Capolongo, S.; Rebecchi, A.; Dettori, M.; Appolloni, L.; Azara, A.; Buffoli, M.; Capasso, L.; Casuccio, A.; Oliveri Conti, G.; D'Amico, A.; et al. Healthy design and urban planning strategies, actions, and policy to achieve salutogenic cities. Int. J. Environ. Res. Public Health 2018, 15, 2698. [CrossRef]

12. Ewing, R.; Handy, S.L. Measuring the unmeasurable: Urban design qualities related to walkability. J. Urban. Des. 2009, 14, 65-84. [CrossRef]

13. Sen, A. The Idea of Justice; Harvard University Press: Cambridge, MA, USA, 2009; ISBN 9780674036130.

14. Lynch, K. The Image Of The City; MIT Press: Cambridge, MA, USA, 1960.

15. Lynch, K. A Theory Of Good City Form; The MIT Press: Cambridge, MA, USA, 1981; ISBN 0-262-12085-2.

16. Kelly, C.E.; Tight, M.R.; Hodgson, F.C.; Page, M.W. A comparison of three methods for assessing the walkability of the pedestrian environment. J. Transp. Geogr. 2011, 19, 1500-1508. [CrossRef]

17. Sitte, C. Der Städtebau nach Seinen Künstlerischen Grundsätzen; Dodi, L., Ed.; Antonio Vallardi Editore: Milano, Italy, 1953. (In Italian)

18. Harvey, D. The right to the city. Int. J. Urban. Reg. Res. 2003, 27, 939-941. [CrossRef]

19. Jacobs, J. The Death and Life of Great American Cities, 1st ed.; Random House: New York, NY, USA, 1961.

20. Lefebvre, H. Writings on Cities; Blackwell Publishers Ltd.: Hoboken, NJ, USA, 1996; ISBN 0-631-19188-7. 
21. Blečić, I.; Cecchini, A.; Trunfio, G.A. Towards Automatic Assessment of Perceived Walkability. In Computational Science and Its Applications - ICCSA 2018, Proceedings of the 18th International Conference on Computational Science and Its Applications Part III, Melbourne, VIC, Australia, 2-5 July 2018; Springer: Cham, Switzerland, 2018; Volume 10962, pp. 351-365.

22. Boulange, C.; Pettit, C.; Gunn, L.D.; Giles-Corti, B.; Badland, H. Improving planning analysis and decision making: The development and application of a Walkability Planning Support System. J. Transp. Geogr. 2018, 69, 129-137. [CrossRef]

23. Maghelal, P.K.; Capp, C.J. Walkability: A review of existing pedestrian indices. URISA J. 2011, 23, 5-19.

24. Moudon, A.V.; Lee, C. Walking and biking: An evaluation of environmental audit instruments. Am. J. Heal. Promot. 2003, 18, 21-37. [CrossRef] [PubMed]

25. Saelens, B.E.; Handy, S.L. Built environment correlates of walking: A review. Med. Sci. Sports Exerc. 2008, 40, S550-S566. [CrossRef]

26. Talen, E.; Koschinsky, J. The walkable neighborhood: A literature review. Int. J. Sustain. L Use Urban. Plan. 2013, 1, 42-63. [CrossRef]

27. Garin, N.; Olaya, B.; Miret, M.; Ayuso-Mateos, J.L.; Power, M.; Bucciarelli, P.; Haro, J.M. Built environment and elderly population health: A comprehensive literature review. Clin. Pract. Epidemiol. Ment. Health 2014, 10, 103-115. [CrossRef]

28. Ewing, R.; Cervero, R. Travel and the built environment: A meta-analysis. J. Am. Plan. Assoc. 2010, 76, 265-294. [CrossRef]

29. Ewing, R.; Cervero, R. Travel and the built environment: A synthesis. Transp. Res. Rec. J. Transp. Res. Board 2001, 1780, 87-114. [CrossRef]

30. Forsyth, A.; Hearst, M.; Oakes, M.; Schmitz, K.H. Design and destinations: Factors influencing walking and total physical activity. Urban. Stud. 2008, 45, 1973-1996. [CrossRef]

31. Glazier, R.H.; Weyman, J.T.; Creatore, M.I.; Gozdyra, P.; Moineddin, R.; Matheson, F.I.; Booth, G.L. Development and validation of an urban walkability index for Toronto, Canada. Toronto Commu. Health Profiles Partnersh. 2012, 18-21. Available online: http://www.torontohealthprofiles.ca/a_documents/aboutTheData/ 12_1_ReportsAndPapers_Walkability_WKB_2012.pdf (accessed on 20 October 2019).

32. Hajna, S.; Dasgupta, K.; Halparin, M.; Ross, N.A. Neighborhood walkability: Field validation of geographic information system measures. Am. J. Prev. Med. 2013, 44, e55-e59. [CrossRef]

33. Iacono, M.; Krizek, K.J.; El-Geneidy, A. Measuring non-motorized accessibility: Issues, alternatives, and execution. J. Transp. Geogr. 2010, 18, 133-140. [CrossRef]

34. Moudon, A.V.; Lee, C.; Cheadle, A.D.; Garvin, C.; Johnson, D.; Schmid, T.L.; Weathers, R.D.; Lin, L. Operational definitions of walkable neighborhood: Theoretical and empirical insights. J. Phys. Act. Health 2006, 3, S99-S117. [CrossRef]

35. Owen, N.; Cerin, E.; Leslie, E.; duToit, L.; Coffee, N.; Frank, L.D.; Bauman, A.E.; Hugo, G.; Saelens, B.E.; Sallis, J.F. Neighborhood walkability and the walking behavior of Australian adults. Am. J. Prev. Med. 2007, 33, 387-395. [CrossRef]

36. Peiravian, F.; Derrible, S.; Ijaz, F. Development and application of the pedestrian environment index (PEI). J. Transp. Geogr. 2014, 39, 73-84. [CrossRef]

37. Talen, E. Pedestrian Access as a measure of urban quality. Plan. Pract. Res. 2002, 17, 257-278. [CrossRef]

38. Saelens, B.E.; Sallis, J.F.; Frank, L.D. Environmental correlates of walking and cycling: Findings from the transportation, urban design, and planning literatures. Ann. Behav. Med. 2003, 2, 80-91. [CrossRef]

39. Buck, C.; Pohlabeln, H.; Huybrechts, I.; De Bourdeaudhuij, I.; Pitsiladis, Y.; Reisch, L.; Pigeot, I. Development and application of a moveability index to quantify possibilities for physical activity in the built environment of children. Health Place 2011, 17, 1191-1201. [CrossRef] [PubMed]

40. D'Alessandro, D.; Arletti, S.; Azara, A.; Buffoli, M.; Capasso, L.; Cappuccitti, A.; Casuccio, A.; Cecchini, A.; Costa, G.; De, A.M.M. Strategies for disease prevention and health promotion in urban areas: The erice 50 charter. Annali di Igiene Medicina Preventiva e di Comunità 2017, 29, 481-493. [CrossRef] [PubMed]

41. Forsyth, A.; Southworth, M. Cities Afoot-Pedestrians, walkability and urban design. J. Urban. Des. 2008, 13, 1-3. [CrossRef]

42. Saelens, B.E.; Sallis, J.F.; Black, J.B.; Chen, D. Neighborhood-Based differences in physical activity: An environment scale evaluation. Am. J. Public Health 2003, 93, 1552-1558. [CrossRef] [PubMed] 
43. Van Dyck, D.; Cardon, G.; Deforche, B.; De Bourdeaudhuij, I. Do adults like living in high-walkable neighborhoods? Associations of walkability parameters with neighborhood satisfaction and possible mediators. Health Place 2011, 17, 971-977. [CrossRef]

44. Van Dyck, D.; Cerin, E.; Conway, T.L.; De Bourdeaudhuij, I.; Owen, N.; Kerr, J.; Cardon, G.; Frank, L.D.; Saelens, B.E.; Sallis, J.F. Perceived neighborhood environmental attributes associated with adults' leisure-time physical activity: Findings from Belgium, Australia and the USA. Health Place 2013, 19, 59-68. [CrossRef]

45. Zuniga-Teran, A.A.; Orr, B.J.; Gimblett, R.H.; Chalfoun, N.V.; Guertin, D.P.; Marsh, S.E. Neighborhood design, physical activity, and wellbeing: Applying the walkability model. Int. J. Environ. Res. Public Health 2017, 14, 76. [CrossRef]

46. Sundquist, K.; Eriksson, U.; Kawakami, N.; Skog, L.; Ohlsson, H.; Arvidsson, D. Neighborhood walkability, physical activity, and walking behavior: The Swedish neighborhood and physical activity (SNAP) study. Soc. Sci. Med. 2011, 72, 1266-1273. [CrossRef]

47. Congiu, T.; Sotgiu, G.; Castiglia, P.; Azara, A.; Piana, A.; Saderi, L.; Dettori, M. Built environment features and pedestrian accidents: An Italian retrospective study. Sustainability 2019, 11, 1064. [CrossRef]

48. Ewing, R.; Dumbaugh, E. The built environment and traffic safety: A review of empirical evidence. J. Plan. Lit. 2009, 23, 347-367. [CrossRef]

49. Handy, S.L.; Niemeier, D.A. Measuring accessibility: An exploration of issues and alternatives. Environ. Plan. A 1997, 29, 1175-1194. [CrossRef]

50. Ruiz-Padillo, A.; Pasqual, F.M.; Larranaga Uriarte, A.M.; Cybis, H.B.B. Application of multi-criteria decision analysis methods for assessing walkability: A case study in Porto Alegre, Brazil. Transp. Res. Part. D Transp. Environ. 2018, 63, 855-871. [CrossRef]

51. Taleai, M.; Taheri Amiri, E. Spatial multi-criteria and multi-scale evaluation of walkability potential at street segment level: A case study of Tehran. Sustain. Cities Soc. 2017, 31, 37-50. [CrossRef]

52. Bejleri, I.; Steiner, R.L.; Fischman, A.; Schmucker, J.M. Using GIS to analyze the role of barriers and facilitators to walking in children's travel to school. URBAN Des. Int. 2011, 16, 51-62. [CrossRef]

53. Towne, S.D.; Won, J.; Lee, S.; Ory, M.G.; Forjuoh, S.N.; Wang, S.; Lee, C. Using Walk Score ${ }^{\mathrm{TM}}$ and neighborhood perceptions to assess walking among middle-aged and older adults. J. Community Health 2016, 41, 1-12. [CrossRef] [PubMed]

54. Cecchini, A.; Congiu, T.; Talu, V.; Tola, G. Mobility policies and extra-small projects for improving mobility of people with autism spectrum disorder. Sustainability 2018, 10, 3256. [CrossRef]

55. Guo, Z.; Loo, B.P.Y. Pedestrian environment and route choice: Evidence from New York City and Hong Kong. J. Transp. Geogr. 2013, 28, 124-136. [CrossRef]

56. Frank, L.D.; Sallis, J.F.; Saelens, B.E.; Leary, L.; Cain, K.; Conway, T.L.; Hess, P.M. The development of a walkability index: Application to the neighborhood quality of life study. Br. J. Sports Med. 2010, 44, 924-933. [CrossRef]

57. Leyden, K.M. Social capital and the built environment: The importance of walkable neighborhoods. Am. J. Public Health 2003, 93, 1546-1551. [CrossRef]

58. Rogers, S.H.; Halstead, J.M.; Gardner, K.H.; Carlson, C.H. Examining walkability and social capital as indicators of quality of life at the municipal and neighborhood scales. Appl. Res. Qual. Life 2011, 6, 201-213. [CrossRef]

59. Talen, E.; Anselin, L. assessing spatial equality: An evaluation of measures of accessibility to public playgrounds. Environ. Plan. 1998, 30, 595-613. [CrossRef]

60. Keyvanfar, A.; Ferwati, M.S.; Shafaghat, A.; Lamit, H. A path walkability assessment index model for evaluating and facilitating retail walking using decision-tree-making (DTM) method. Sustainability 2018, 10, 1035. [CrossRef]

61. Rebecchi, A.; Buffoli, M.; Dettori, M.; Appolloni, L.; Azara, A.; Castiglia, P.; D’Alessandro, D.; Capolongo, S. Walkable environments and healthy urban moves: Urban context features assessment framework experienced in Milan. Sustainability 2019, 11, 2778. [CrossRef]

62. Krizek, K.J. Operationalizing neighborhood accessibility for land use-travel behavior research and regional modeling. J. Plan. Educ. Res. 2003, 22, 270-287. [CrossRef]

63. Cervero, R.; Kockelman, K. Travel demand and the 3Ds: Density, diversity, and design. Transp. Res. Part D Transp. Environ. 1997, 2, 199-219. [CrossRef] 
64. Lee, C.; Moudon, A.V. The 3Ds + R: Quantifying land use and urban form correlates of walking. Transp. Res. Part. D Transp. Environ. 2006, 11, 204-215. [CrossRef]

65. Gardner, K.; Johnson, T.; Buchan, K.; Pharoah, T. Developing a pedestrian strategy for London. In Proceedings of the Transport Policy and Its Implementation, Uxbridge, UK, 2-6 September 1996; p. 400.

66. Pikora, T.; Giles-Corti, B.; Bull, F.; Jamrozik, K.; Donovan, R. Developing a framework for assessment of the environmental determinants of walking and cycling. Soc. Sci. Med. 2003, 56, 1693-1703. [CrossRef]

67. Pikora, T.J.; Bull, F.C.L.; Jamrozik, K.; Knuiman, M.; Giles-Corti, B.; Donovan, R.J. Developing a reliable audit instrument to measure the physical environment for physical activity. Am. J. Prev. Med. 2002, 23, 187-194. [CrossRef]

68. Su, S.; Zhou, H.; Xu, M.; Ru, H.; Wang, W.; Weng, M. Auditing street walkability and associated social inequalities for planning implications. J. Transp. Geogr. 2019, 74, 62-76. [CrossRef]

69. Zuniga-Teran, A.A.; Orr, B.J.; Gimblett, R.H.; Chalfoun, N.V.; Going, S.B.; Guertin, D.P.; Marsh, S.E. Designing healthy communities: A walkability analysis of LEED-ND. Front. Archit. Res. 2016, 433-452. [CrossRef]

70. Handy, S. Critical assessment of the literature on the relationships among transportation, land use, and physical activity. Transp. Res. Board Inst. Med. Comm. Phys. Act. Health Transp. Land Use Resour. 2005, 282, $1-81$.

71. Amaratunga, D.; Baldry, D.; Sarshar, M.; Newton, R. Quantitative and qualitative research in the built environment: Application of "mixed" research approach. Work Study 2002, 51, 17-31. [CrossRef]

72. Lin, L.; Moudon, A.V. Objective versus subjective measures of the built environment, which are most effective in capturing associations with walking? Health Place 2010, 16, 339-348. [CrossRef] [PubMed]

73. Klosterman, R.E. Planning Support Systems: A New Perspective on Computer-Aided Planning. J. Plan. Educ. Res. 1997, 17, 45-54. [CrossRef]

74. Papa, E.; Silva, C.; Te Brömmelstroet, M.; Hull, A. Accessibility instruments for planning practice: A review of European experiences. J. Transp. Land Use 2016, 9, 57-75. [CrossRef]

75. Russo, P.; Costabile, M.F.; Lanzilotti, R.; Pettit, C.J. Usability of Planning Support Systems: An Evaluation Framework. In Planning Support Systems and Smart Cities; Geertman, S., Ferreira, J., Jr., Goodspeed, R., Stillwell, J., Eds.; Springer International Publishing: Cham, Germany, 2015; pp. 337-353. ISBN 978-3-319-18368-8.

76. Te Brömmelstroet, M. Performance of planning support systems: What is it, and how do we report on it? Comput. Environ. Urban. Syst. 2013, 41, 299-308. [CrossRef]

77. Blečić, I.; Talu, V. In Pedestrian Mobility as a Fundamental Urban Right: The Possible Contribution of Children to Urban Walkability. In Proceedings of the Seventh International Conference on Informatics and Urban and Regional Planning INPUT2012, Cagliari, Italy, 10-12 May 2020; Campagna, M., de Montis, A., Isola, F., Lai, S., Pira, C., Zoppi, C., Eds.; FrancoAngeli: Milano, Italy, 2012; pp. 1287-1295.

78. Blečić, I.; Cecchini, A.; Talu, V. The Capability Approach in Urban Quality of Life and Urban Policies: Towards a Conceptual Framework. In City Project and Public Space; Serreli, S., Ed.; Springer International Publishing: Dordrecht, The Netherlands, 2013; pp. 269-288. ISBN 978-94-007-6037-0.

79. Ewing, R.; Clemente, O. Measuring Urban Design: Metrics for Livable Places; Island Press: Washington, DC, USA, 2013; ISBN 9781610912099.

80. Bader, M.D.M.; Mooney, S.J.; Lee, Y.J.; Sheehan, D.; Neckerman, K.M.; Rundle, A.G.; Teitler, J.O. Development and deployment of the Computer Assisted Neighborhood Visual Assessment System (CANVAS) to measure health-related neighborhood conditions. Health Place 2015, 31, 163-172. [CrossRef]

81. Moura, F.; Cambra, P.; Gonçalves, A.B. Measuring walkability for distinct pedestrian groups with a participatory assessment method: A case study in Lisbon. Landsc. Urban. Plan. 2017, 157, 282-296. [CrossRef]

82. Oswald Beiler, M.R.; Phillips, B. Prioritizing Pedestrian Corridors Using Walkability Performance Metrics and Decision Analysis. J. Urban. Plan. Dev. 2016, 142, 4015009. [CrossRef]

83. Blečić, I.; Cecchini, A.; Congiu, T.; Fancello, F.; Fancello, G.; Trunfio, G.A. Walkability Explorer: Application to a Case-Study. Lecture Notes in Computer Science (including subseries Lecture Notes in Artificial Intelligence and Lecture Notes in Bioinformatics); TeMA Journal of Land Use Mobility and Environment: Naples, Italy, 2015.

84. Emery, J.; Crump, C.; Bors, P. Reliability and validity of two instruments designed to assess the walking and bicycling suitability of sidewalks and roads. Am. J. Health Promot. 2003, 18, 38-46. [CrossRef]

85. Ghani, N.A.; Shah, M.Z.; Mokhtar, S. Incorporating pedestrian index into Googlemaps. Plan. Malaysia 2013, $11,119-136$. 
86. Handy, S.L.; Clifton, K.J. Evaluating neighborhood accessibility: Possibilities and practicalities. J. Transp. Stat. 2001, 4, 67-78.

87. Koohsari, M.J.; Kaczynski, A.T.; Giles-Corti, B.; Karakiewicz, J.A. Effects of access to public open spaces on walking: Is proximity enough? Landsc. Urban. Plan. 2013, 117, 92-99. [CrossRef]

88. Ball, K.; Bauman, A.E.; Leslie, E.; Owen, N. Perceived environmental aesthetics and convenience and company are associated with walking for exercise among Australian adults. Am. J. Prev. Med. 2001, 33, 434-440. [CrossRef] [PubMed]

89. Day, K.; Boarnet, M.; Alfonzo, M.; Forsyth, A. The Irvine-Minnesota Inventory to measure built environments. Am. J. Prev. Med. 2006, 30, 144-152. [CrossRef] [PubMed]

90. Giles-Corti, B.; Macaulay, G.; Middleton, N.; Boruff, B.; Bull, F.; Butterworth, I.; Badland, H.; Mavoa, S.; Roberts, R.; Christian, H. Developing a research and practice tool to measure walkability: A demonstration project. Health Promot. J. Aust. 2014, 25, 160-166. [CrossRef] [PubMed]

91. Blecic, I.; Canu, D.; Cecchini, A.; Congiu, T.; Fancello, G. Walkability and street intersections in rural-urban fringes: A decision aiding evaluation procedure. Sustainability 2017, 9, 883. [CrossRef]

92. Lwin, K.K.; Murayama, Y. Modelling of urban green space walkability: Eco-friendly walk score calculator. Comput. Environ. Urban. Syst. 2011, 35, 408-420. [CrossRef]

93. Carr, L.J.; Dunsiger, S.I.; Marcus, B.H. Walk score ${ }^{\mathrm{TM}}$ as a global estimate of neighborhood walkability. Am. J. Prev. Med. 2010, 39, 460-463. [CrossRef]

94. Blečić, I.; Canu, D.; Cecchini, A.; Congiu, T.; Fancello, G.; Mauro, S.; Sacerdotti, S.L.; Trunfio, G.A. Coupling Surveys with GPS Tracking to Explore Tourists' Spatio-Temporal Behaviour. Proceeding of the Computational Science and Its Applications (ICCSA 2016) 16th International Conference, Beijing, China, 4-7 July 2016; LNCS: Beijing, China; Volume 9789, pp. 150-160.

95. Tal, G.; Handy, S.L. Measuring Nonmotorized Accessibility and Connectivity in a Robust Pedestrian Network. Transp. Res. Rec. J. Transp. Res. Board 2012, 2299, 48-56. [CrossRef]

96. LEED ND Certification System. Available online: https://www.usgbc.org/leed/rating-systems/neighborhooddevelopment (accessed on 21 April 2020).

97. Walkonomics.com. Available online: www.walkonomics.com (accessed on 20 October 2019).

98. Walkshed.org. Available online: www.walkshed.org (accessed on 20 October 2019). 